
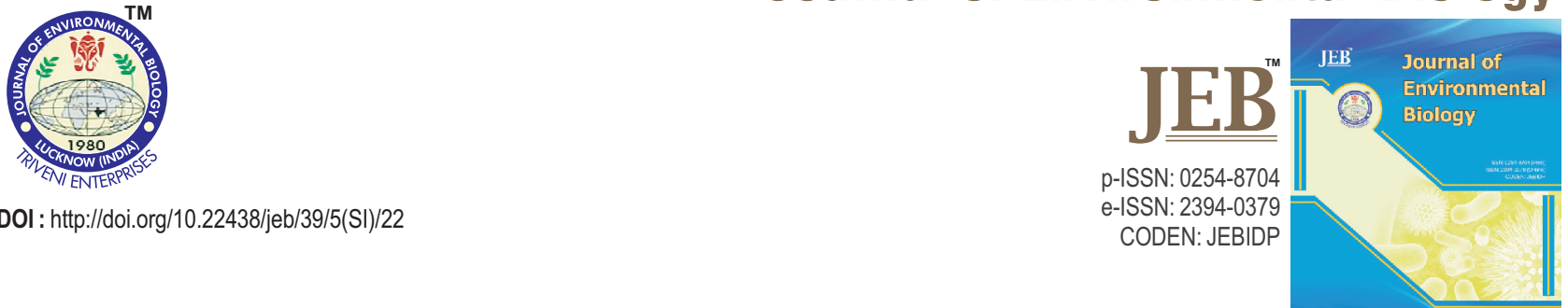

\title{
Effects of bottom substratum on survival and growth of early juveniles of blue swimming crab, Portunus pelagicus (Linnaeus, 1758) in captivity
}

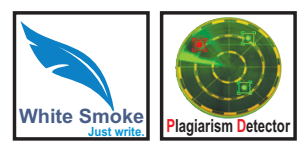

\section{Authors Info}

S.M. Shoyaib Kohinoor', A. Arshad"*, S.M. Nurul Amin', M. Aminur Rahman ${ }^{2.3}$, Mohd. S. Kamarudin' and J.A. Al Khayat ${ }^{4}$

'Department of Aquaculture, Faculty of Agriculture, Universiti Putra Malaysia, 43400 UPM Serdang, Selangor Darul Ehsan, Malaysia

${ }^{2}$ World Fisheries University Pilot Programme, Pukyong National University (PKNU), 45 Yongso-ro, Nam-gu, Busan 48513, Korea

${ }^{3}$ Laboratory of Marine Biotechnology, Institute of Bioscience, Universiti Putra Malaysia, 43400 UPM Serdang, Selangor Darul Ehsan, Malaysia

${ }^{4}$ Department of Biological and Environmental Sciences, College of Arts and Science, Qatar University, P.O. Box 2713, Doha, Qatar

*Corresponding Author Email : azizar.upm@gmail.com

Key words

Bottom substratum

Cannabalism

Captivity

Growth rate

Portunus pelagicus

Publication Info

Paper received : 25.05.2017

Revised received : 20.08.2017

Re-revised received : 15.10.2017

Accepted : 28.12.2017

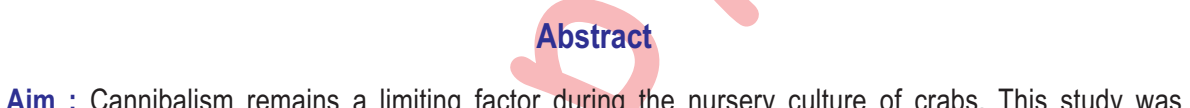

Aim : Cannibalism remains a limiting factor during the nursery culture of crabs. This study was undertaken to improve the rearing techniques by investigating the impact of bottom substratum on crablet survival and growth. The knowledge gained from the research will be useful for the communal seed culture and development of crab farming, which are important factors regarding farmers' job stability in the future.

Methodology : Blue swimming crab, Portunus pelagicus (first settled (C1 crabs); initial average weight and SD of $0.02 \pm 0.01 \mathrm{~g})$ were cultured in glass aquarium $(90 \times 44 \times 34 \mathrm{~cm})$ and their survival and growth were assessed after 22 days of culture in four types of substratum such as control (none), sand, soil, or sand + soil. All treatments had 25 juvenile crabs, each of which was triplicated. Feeding was done twice a day $(9$ am and 5 pm) to apparent satiation.

Results : Survival of early juvenile crabs cultured with sand was substantially higher at $65.33 \pm 6.11 \%$ than those cultured with soil, sand + soil or control at $29.33 \pm 10.07 \%$, $28.00 \pm 8.00 \%$, and $21.33 \pm$ $6.11 \%$, respectively. Growth performance (such as final weight, weight gain and specific growth rate) of the early juvenile of $P$. pelagicus in all treatments were not significantly different $(p>0.05)$.

Interpretation : Overall, the best survival was achieved with sand substratum and can be recommended as a mean of reducing cannibalism during the early nursery rearing of blue swimming crab juveniles under captive culture conditions.
Suitable bottom substratum for early juvenile blue swimming crab, Portunus pelagicus

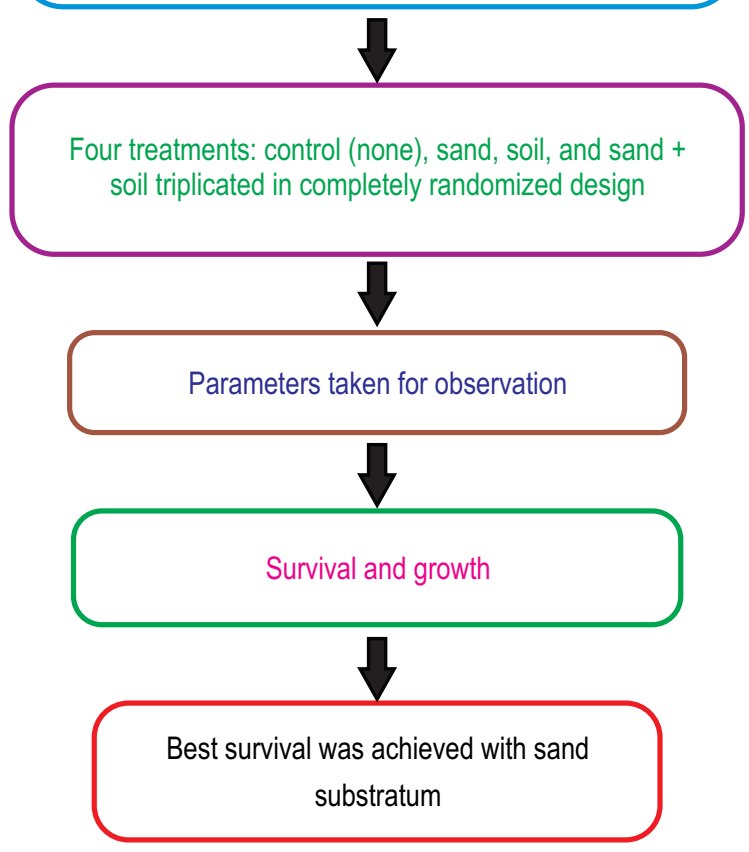




\section{Introduction}

The blue swimming crab, Portunus pelagicus, a commercially important species, belongs to family Portunidae and is distributed throughout the coastal tropical waters in the western Indian Ocean and the Eastern Pacific (FAO, 2009). Most of the market demands for this species is met through the capture fisheries. However, due to over fishing and marine pollution, the natural resource and fisheries production of $P$. pelagicus has shown a downward trend in 2009. Therefore, aquaculture is a recognized way to help fulfill market demands for crab products.

Currently, many Asian countries are actively involved in Portunus crab culture and associated research, e.g., the Philippines, Indonesia, India, Australia, and Malaysia (Romano and Zeng, 2006, 2010; Oniam and Taparhudee, 2010; Oniam et al., 2009, 2010; Wu et al., 2010; Roslan et al., 2016; Meng et al., 2018). While the larivculture methods of $P$. pelagicus have been developed, the main bottleneck to their commercial farming on a mass scale includes excessive cannibalism (Romano and Zeng, 2017). It is possible to eliminate cannibalism altogether by culturing them in individual cells (Ebert et al., 1975; Van Olst et al., 1975), however, this is labor intensive and largely viewed as impractical during their early nursery culture (Roslan et al., 2016). Alternative strategies, such as providing different substrates have been tried and can be effective in reducing cannibalism. For example, combinations of both sand and seaweed were more effective in improving survival among early $P$. pelagicus juveniles compared only with using seaweed, netting or bare substratum (Ravi and Manisseri, 2012). At present, no information is available in comparing different substratum types during the early nursery culture of $P$. pelagicus, which may further improve their survivability and production.

Thus the objective of this study was to improve the rearing techniques by investigating the impact of bottom substratum on crablet survival and growth. The knowledge gained from the research will be useful for the communal seed culture and development of crab farming.

\section{Materials and Methods}

Experimental site : This experiment was carried out at the hatchery complex in the Marine Science Center of UPM, Port Dickson, Negeri Sembilan, Malaysia during December, 2016.

Seawater for broodstock, larvae and crablet culture : Ultraviolet-treated seawater was filtered through a $10 \mu \mathrm{m}$ nylon net and then disinfected with chlorine for 24 hrs to provide hygienic source of water. The treated water was then supplemented with EDTA to chelate any heavy metals followed by chlorine neutralization with sodium thiosulphate (Romano and Zeng, 2006).

Brood stock maintenance and hatching : In total, five berried females weighing $145 \mathrm{~g}$ to173 $\mathrm{g}$ were collected from coastal waters of Port Dickson, Seremban, Malaysia $\left(2^{\circ} 31^{\prime} \mathrm{N}\right.$ and $101^{\circ}$ $480^{\prime} \mathrm{E}$ ) and were transported to the Center of Marine Science of UPM, Port Dickson, Malaysia. The collected females were disinfected according to Romano and Zeng (2006) and one berried crab was placed per 100 I capacity hatching tank (static system) with adequate aeration, and $80 \%$ water was exchanged daily. Berried females were not fed and were monitored daily for hatching. After the larvae hatched, the water volume was reduced to 50 I with a siphon attached to a mesh filter.

Larvae culture tanks were filled with disinfected water to $1000 \mathrm{I}$ and had one submersible heater in order to maintain the constant temperature of $30^{\circ} \mathrm{C}$. Actively moving larvae were collected and used for stocking in rearing tanks to produce crablets according to Romano and Zeng (2006). When the crabs first settled ( $\mathrm{C} 1 \mathrm{crabs}$ ), the healthy ones were collected and placed together into glass aquaria $(90 \times 44 \times 34 \mathrm{~cm})$ for the experiment.

Experimental design and substratum : A total of 12 glass aquaria were used and each aquarium was stocked with $25 \mathrm{C} 1$ crabs, which had an mean wet weight of $0.02 \pm 0.01 \mathrm{~g}$, carapace length of $3.60 \pm 0.01 \mathrm{~mm}$ and carapace width of $6.05 \pm 0.02 \mathrm{~mm}$. There were four treatments (each in three triplicates), arranged in a completely randomized design, that consisted of three substratum types viz. sand, soil and sand + soil (mix), while no substrate served as control. The substratum was aged 15 days prior to start of the experiment.

After stocking the crabs, they were fed ad libitum with commercial shrimp pellets twice daily. The treated seawater (32-33 ppt) was used with a daily water exchange of $20 \%$. During this time, any leftover feeds were removed. Water $\mathrm{pH}$ was maintained at a range between 7.5 and 8.0 using calcium carbonate whenever necessary. Gentle aeration was provided to maintain dissolved oxygen (DO) level in each aquarium throughout the experiment. After 22 days of rearing, the final carapace width and length of the crabs were measured using a digital caliper ( $0.01 \mathrm{~mm}$; Mitutoyo, Japan). Final wet weights were measured using a digital balance to the nearest $0.01 \mathrm{~g}$, and percentage of survival was estimated.

Data collection : At the end of experiment, final carapace length and width, growth rate and wet weight were taken for determination of growth parameters such as weight gain and specific growth rate (SGR). The weight gain and SGR were estimated by the following formulas:

SGR $(\% /$ day $)=[$ final body weight $(\mathrm{g})-$ initial body weight $(\mathrm{g}) /$ Culture period (day) $] \times 100$

Weight gain $(\%)=$ [final body weight $(\mathrm{g})-$ initial body weight $(\mathrm{g}) /$ initial body weight $(\mathrm{g})] \times 100$ 
Table 1 : Growth performances and survival of early juveniles of Portunus pelagicus reared in captivity for 22 days using different substrates

\begin{tabular}{lllll}
\hline Parameters & Control & Sand & Soil & Sand + Soil \\
\hline Initial weight $(\mathrm{g})$ & $0.02 \pm 0.01^{\mathrm{a}}$ & $0.02 \pm 0.01^{\mathrm{a}}$ & $0.02 \pm 0.01^{\mathrm{a}}$ & $0.02 \pm 0.01^{\mathrm{a}}$ \\
Final weight $(\mathrm{g})$ & $0.21 \pm 0.06^{\mathrm{a}}$ & $0.19 \pm 0.03^{\mathrm{a}}$ & $0.18 \pm 0.04^{\mathrm{a}}$ & $0.17 \pm 0.06^{\mathrm{a}}$ \\
Weight gain $(\mathrm{g})$ & $0.18 \pm 0.06^{\mathrm{a}}$ & $0.17 \pm 0.03^{\mathrm{a}}$ & $0.16 \pm 0.04^{\mathrm{a}}$ & $0.15 \pm 0.06^{\mathrm{a}}$ \\
SGR (\%) & $0.83 \pm 0.27^{\mathrm{a}}$ & $0.77 \pm 0.13^{\mathrm{a}}$ & $0.71 \pm 0.02^{\mathrm{a}}$ & $0.71 \pm 0.29^{\mathrm{a}}$ \\
Carapace width (mm) & $13.25 \pm 1.13^{\mathrm{a}}$ & $13.02 \pm 0.85^{\mathrm{a}}$ & $12.26 \pm 1.05^{\mathrm{a}}$ & $12.54 \pm 2.50^{\mathrm{a}}$ \\
Carapace length (mm) & $7.04 \pm 0.62^{\mathrm{a}}$ & $6.87 \pm 0.46^{\mathrm{a}}$ & $6.43 \pm 0.55^{\mathrm{a}}$ & $6.6 \pm 1.28^{\mathrm{a}}$ \\
Survival (\%) & $21.33 \pm 6.11^{\mathrm{b}}$ & $65.33 \pm 6.11^{\mathrm{a}}$ & $29.33 \pm 10.07^{\mathrm{b}}$ & $28.00 \pm 8.00^{\mathrm{b}}$ \\
\hline
\end{tabular}

All values represent mean $\pm S D$. Mean values bearing the same superscripts in the same row are not significantly different $(p>0.05)$

At the end of the experiment, percent survival of crablet was calculated by the following formula:

Survival $=$ [total number of survived crabs / initial number of stocked crabs] $\times 100$

Data analysis : Mean values of different parameters (viz., body weight gain, survival rate, specific growth rate, and carapace length and carapace width growth rate) from different replicates for each treatment were calculated by Microsoft Office Excel 2010. One-way ANOVA was performed to know the effects of different substrata on growth performance and survival of crab. Duncan's multiple range test (DMRT) was used to see the significant differences between means at $p<0.05$ level of significance by the computerized SPSS Version 16.

\section{Results and Discussion}

The highest mean survival was achieved with sand substratum (65.33\%), followed by soil substratum $(29.33 \%)$ and bottom sand +soil (mix) substratum $(28.00 \%)$, while the lowest survival was noted in the control $(21.33 \%)$. Survival in the sand treatment and control was significantly different $(p<0.05)$, while the rest of the treatments were not significantly different $(p>0.05)$ from each other (Fig.1).

The highest mean final body weight (b.w.), weight gain and SGR of juvenile crabs were observed in control, followed by sand and soil, while the lowest in sand + soil (mix) treatments (Table 1). The lowest body weight $(0.17 \pm 0.06 \mathrm{~g})$, weight gain $(788.41 \pm 326.48 \%)$ and SGR $(0.71 \pm 0.29 \%)$ were observed in the sand + soil (mix) treatments. However, the growth performance was not significantly different among the treatments.

The significantly higher crab survival in the sand substrate treatment seems most likely due to lower incidences of cannibalism. Burrowing habits develop from the first crab instar onwards (Maheswarudu et al., 2008), which was also observed in this study. Therefore, the sand substrate probably allowed the crabs to burrow more effectively, and thus hide from their conspecifics. In contrast, when no substrate was provided, the newly molted crablets will be exposed and easily be targeted for cannibalism. The provision of dark clay paving stones was shown to reduce the ferocious behavior and cannibalism in P. pelagicus by providing more areas for the crabs to hide (Marshall et al., 2005). Similarly, artificial substrates has been found to increase survival in other crustacean juveniles, presumably by allowing more newly molted individuals to hide during this vulnerable stage (Zmora et al., 2005; Arnold et al., 2006). It has also been found that for other crabs including the mud crab (Scylla serrata), brown crab (Cancer pagurus) and the red king crab (Paralithodes camtschaticus), there was less cannibalism when complex substrates were provided in the form of shells, seaweeds and pebbles compared to sand or soil bottom (Rodriguez et al., 2007; Amaral et al., 2009; Long et al., 2012).

Growth of crabs is usually expressed in carapace width or length increment (Pinheiro and Fransozo, 1993; Takeuchi et al., 1999). In our study, substrate type did not have any effect on growth performance, despite decreases in survival and associated stocking densities among the treatments. Moreover, it is known that the consumption of conspecifics is generally assumed to provide better nutrition (Romano and Zeng, 2017). Van Olst el al. (1975) also found no significant difference in American lobster growth cultured in substrates, as these animals are known to be less cannibalistic than crabs.

It can be concluded that less cannibalism was found when cultured with sand substratum. Therefore, sand substratum is recommended for early nursery culture of blue swimming crab in captivity.

\section{Acknowledgments}

The authors are grateful to those who have directly and indirectly contributed to this study, especially to the staffs of Center of Marine Science (COMAS), Port Dickson. This study was funded by a grant from Universiti Putra Malaysia (UPM projectno. GP-IPB/2014/9440402). 


\section{References}

Amaral. V., J. Paula, S. Hawkins and S. Jenkins: Cannibalistic interactions in two co-occurring decapod species: Effects of density, food, alternative prey and habitat. J. Exp. Mar. Biol. Ecol., 368, 88-93 (2009).

Arnold, S.J., M.J. Sellars, P.J. Crocos and G.J. Coman: Intensive production of juvenile tiger shrimp Penaeus monodon: An evaluation of stocking density and artificial substrates. Aquaculture, 261, 890-896 (2006).

Ebert, E.E., O.K. Randolph and W.H. Arthur: Observations on the larval hatching success of Dungeness crab, Cancer magister, from the Eureka-Crescent City region. Calif. Dep. Fish Game Mar. Resour. Tech. Rep., 29, 1-14 (1975).

FAO: Globefish Commodity Update: Crab. Fishery Industries Division, Viale delle Terme di Caracalla, Rome, Italy (2009).

Kovatcheva, N., A. Epelbaum, A. Kalinin, R. Borisov and R. Lebedev: Early life history stages of the Red King Crab Paralithodes camtschaticus (Tilesius, 1815). Biology and Culture. VINRO Publishing (2006).

Long, C. W., J. Popp, K. M. Swiney and S. B. Van Sant. Cannibalism in red king crab, Paralithodes camtschaticus (Tilesius, 1815): Effects of habitat type and predator density on predator functional response. J. Exp. Mar. Biol. Ecol., 422-423, 101-106 (2012).

Maheswarudu, G., J. Jose, K. R. M. Nair, M. R. Arputharaj, A. Ramakrishna, A. Vairamani and N. Ramamoorthy: Evaluation of the seed production and grow out culture of blue swimming crab Portunus pelagicus (Linnaeus, 1758) in India. Indian J. Mar. Sci., 37,313-321 (2008).

Marshall, S., K. Warburton, B. Paterson and D. Mann: Cannibalism in juvenile blue-swimmer crab Portunus pelagicus (Linnaeus, 1766): Effects of body size, moult stage and refuge availability. Appl. Animal Behav. Sci., 90, 65-82 (2005).

Meng, X., X. Zhang, J. Li and P. Liu: Identification and comparative profiling of ovarian and testicular microRNAs in the swimming crab Portunus trituberculatus. Gene, 640, 6-13 (2018).

Oniam, V. and W. Taparhudee: Physical relationship on fecundity and hatching rate of blue swimming crab (Portunus pelagicus Linnaeus, 1758) from broodstocks's earthen ponds. In: The Proceeding of 48th Kasetsart University Annual Conference: Fisheries. Bangkok, Thailand, pp. 99-107 (2010).

Oniam, V., U. Buathee, L. Chuchit and T. Wechakama: Growth and sexual maturity of blue swimming crab (Portunus pelagicus Linnaeus, 1758) reared in the earthen ponds. Kasetsart Uni. Fish. Res. Bull., 34, 20-27 (2010).

Oniam, V., T. Wechakama and S. Vichaimuang: The survival rate of blue swimming crab (Portunus pelagicus Linnaeus, 1758) larvae from broodstock's earthen ponds. In: Proceeding of $47^{\text {th }}$ Kasetsart
University Annual Conference: Fisheries, Bangkok, Thailand pp. 381-387 (2009).

Pinheiro, M. and A. Fransozo: Relative growth of the speckled swimming crab Arenaeus cribrarius (Lamarck, 1818) (Brachyura Portunidae), near Ubatuba, State of Sao Paulo, Brazil. Crustaceana, 65, 365-376. (1993).

Quinitio, E.T., J.J. De-la Cruz, M.R.R. Eguia, F.D. Parado-Estepa, G. Pates and C.R. Lavilla-Pitogo: Domestication of the mud crab Scylla serrata. Aquacult. Int., 19, 237-250 (2011).

Ravi, R. and M.K. Manisseri: Efficiency of shelters in reducing cannibalism among juveniles of the marine blue swimming crab, Portunus pelagicus. Isr. J. Aquacult., 64, 1-6 (2012).

Rodriguez, E.M., F.D. Parado-Estepa and E.T. Quinitio: Extension of nursery culture of Scylla serrata (Forsskal) juveniles in net cages and ponds. Aquacult. Res., 38, 1588-1592 (2007).

Romano, N. and C. Zeng: The effects of salinity on the survival, growth and haemolymph osmolality of early juvenile blue swimmer crabs, Portunus pelagicus. Aquaculture, 260, 151-162 (2006).

Romano, N. and C. Zeng: Survival, osmoregulation and ammonia-N excretion of blue swimmer crab, Portunus pelagicus, juveniles exposed to different ammonia-N and salinity combinations. Comp. Biochem. Physiol., 151, 222-228 (2010).

Romano, N. and C. Zeng. Cannibalism among decapod crustaceans and implications for their aquaculture: A review on its prevalence, influencing factors and mitigating methods. Rev. Fish. Sci. Aquacult., 25, 42-69 (2017).

Roslan, S., S. Taher, F. Ehteshamei, A. Arshad and N. Romano: Effects of dietary peppermint (Mentha piperita) essential oil on survival, growth, cannibalism and histopathology of the swimming crab, Portunus pelagicus, juveniles. J. Environ. Biol., 37, 785-790 (2016).

Shleser, R. and J.G. Tchobanoglous: The American lobster as a model for the continuous production of quality seafood through aquaculture. J. Mar. Tech. Soc., 8,4-8 (1974).

Takeuchi, T., N. Satoh, S. Sekiya, T. Shimizu and T. Watanabe: The effect of dietary EPA and DHA on the molting rate of larval swimming crab Portumus trituberculaus. Nippon Suisan Gakkaishi, 65, 998-1004 (1999).

Van Olst, J.C., J.M. Carlberg and R.F. Ford: Effects of substrate type and other factors on the growth survival and cannibalism of juvenile Homarus americanus in mass rearing system. J. World Aquacul. Soc., 6, 261-274(1975).

Wu, X., Y. Cheng, C. Zeng, C. Wang and Z. Cui: Reproductive performance and offspring quality of the first and the second brood of female swimming crab, Portunus trituberculatus. Aquaculture, 303, 94-100(2010).

Zmora, O., A. Findiesen, J. Stubblefield, V. Frenkel and Y. Zohar: Largescale juvenile production of the blue crab Callinectes sapidus. Aquaculture, 244, 129-139 (2005). 